\title{
Low Expression of Bax Predicts Poor Prognosis in Resected Non-small Cell Lung Cancer Patients with Non-squamous Histology ${ }^{\dagger}$
}

\author{
Seong Hyun Jeong1, Hyun-Woo Lee', Jae Ho Han², Seok Yun Kang ${ }^{1,3}$, Jin-Hyuk Choi ${ }^{1,3}$, Youn Mu Jung', \\ Ho Choi ${ }^{4}$, Young Taek Oh',5, Kwang Joo Park ${ }^{3,6}$, Sung Chul Hwang ${ }^{3,6}$, Seung Soo Sheen ${ }^{3,6,7}$, Yoon Jung Oh, \\ Jang Hee Kim² and Ho-Yeong Lim ${ }^{8}$
}

${ }^{1}$ Department of Hematology-Oncology, ${ }^{2}$ Department of Pathology, ${ }^{3}$ Lung Cancer Center, ${ }^{4}$ Department of Chest Surgery, ${ }^{5}$ Department of Radiation Oncology, ${ }^{6}$ Department of Pulmonary and Critical Care Medicine, ${ }^{7}$ Section of Clinical Epidemiology and Biostatistics in Clinical Trial Center, Ajou University School of Medicine, Suwon and ${ }^{8}$ Division of Hematology-Oncology, Department of Medicine, Samsung Medical Center, Sungkyunkwan University School of Medicine, Seoul, Republic of Korea

Received June 11, 2008; accepted August 2, 2008; published online September 4, 2008

\begin{abstract}
Objective: The present study evaluated the prognostic significance of apoptosis-related proteins p53, Bax and galectin-3 in patients with non-small cell lung cancer (NSCLC) treated with surgical resection.

Methods: We investigated the expression of these proteins and their association with clinicopathologic characteristics including disease-free survival (DFS) and overall survival (OS) in 205 NSCLC patients who underwent surgical resection (Stage I, 97; II, 46; IIIA, 45; IIIB, 17) using immunohistochemistry. Eighty-eight patients (43\%) received adjuvant treatment (chemotherapy: 8, radiotherapy: 24, both: 56 ).

Results: High expressions of Bax, p53 and galectin-3 were observed in 48 (23\%), 81 (40\%) and $105(51 \%)$ patients, respectively. Low expression of Bax was significantly associated with male gender, squamous cell histology and low expression of galectin-3. Five-year DFS and OS of total patients were 37 and $46 \%$, respectively. High expressions of p53 and galectin-3 were not associated with poor DFS or OS, and no significant correlation existed between low expression of Bax and outcome of patients. However, in patients with non-squamous histology (108 patients), low expression of Bax was a significant independent predictor of poor DFS $(P=0.017)$ and OS $(P=0.037)$. In addition, in patients with Stage II or III disease, low expression of Bax significantly correlated with poor DFS $(P=0.004)$. It was also the most significant independent poor prognostic factor second only to a large primary tumor size in Stage II or III patients with non-squamous histology.

Conclusions: Low expression of Bax was significantly associated with poor prognosis in resected NSCLC patients with non-squamous histology.
\end{abstract}

Key words: non-small cell lung cancer - Bax - prognosis

\section{INTRODUCTION}

Lung cancer is the most common malignancy in many countries and it has become the number one cause of cancer

For reprints and all correspondence: Jin-Hyuk Choi, Department of Hematology-Oncology, Ajou University School of Medicine, Suwon 443-721, Republic of Korea. E-mail: jhchoimd@ajou.ac.kr

${ }^{\dagger}$ Presented in part at the 42nd Annual Meeting of American Society of Clinical Oncology, Atlanta, Georgia, 2006. death in Korea, surpassing gastric cancer $(1,2)$. Majority of lung cancer patients has non-small cell type, in which surgical resection is still the mainstay of the curative treatment (2). However, the prognosis of patients with non-small cell lung cancer (NSCLC) is still poor despite surgical treatment $(2,3)$. Recently, several phase III trials demonstrated improved survival with adjuvant chemotherapy, especially in patients with Stage II or III disease (4-7). Therefore, the determination of parameters that may identify those patients 
who would benefit from adjuvant chemotherapy, and those who would not, has strong clinical implications. Apoptosis-related proteins are important candidates for such parameters, because apoptosis is the predominant mechanism in which chemotherapy and radiotherapy kill the cancer cells (8). Among several proteins involved in apoptosis, the fine interplay between the anti-apoptotic members of the Bcl-2 family and the death-promoting members such as Bax and p53 has been suggested as the most important process (8). $\mathrm{BH} 3$-only proteins or $\mathrm{p} 53$ directly or indirectly activate the Bax protein, which permeabilizes the mitochondrial outer membrane, leading to the activation of downstream apoptosis signaling pathways $(8,9)$. In addition, galectin-3, which belongs to a family of the galactoside-binding protein-3, and is structurally and functionally similar to Bcl-2, is known to protect cells from apoptosis by various stimuli (10). Therefore, genetic defects in these proteins may not only result in intrinsic biologic aggressiveness, but also lead to resistance to the cytotoxic effects of chemotherapy and radiotherapy $(8,11-13)$. We evaluated the prognostic significance of apoptosis-related proteins p53, Bax and galectin-3 in NSCLC patients treated with surgical resection with or without adjuvant treatment.

\section{PATIENTS AND METHODS}

PATIENTS

Two hundred and five patients who underwent resection of primary NSCLC at Ajou University Medical Center between
September 1996 and December 2002 were eligible to be included in this retrospective study. Patients with a history of cancer from a non-pulmonary origin were included if the disease was cured. Exclusion criteria included patients with history of previous lung cancer, a Stage IV disease and those treated preoperatively with either chemotherapy or radiotherapy. Before operation, each patient underwent the following staging procedures: chest radiography, chest computed tomography (CT) scan and hematologic and biochemical profiles. The American Joint Committee on Cancer staging was used for post-operative pathologic staging of the patients (14). This research protocol was approved by the Institutional Review Board of the Ajou University Medical Center, Suwon, Korea.

\section{Chemotherapy}

In the majority of patients in Stage II or III, adjuvant chemotherapy was performed according to the discretion of physicians. Although adjuvant chemotherapy regimens were not uniformly applied, all, except three, patients received cisplatin-based chemotherapy (gemcitabine, tegracil and gemcitabine/carboplatin, respectively). The most commonly administered regimen ( 24 patients) consisted of two cycles of etoposide/cisplatin chemotherapy followed by concurrent chemoradiotherapy with cisplatin. In this regimen, etoposide $100 \mathrm{mg} / \mathrm{m}^{2} /$ day (Days $1-3$ ) and cisplatin $20 \mathrm{mg} / \mathrm{m}^{2} /$ day (Days 1-4) were administered every 3 weeks, while concurrent chemoradiotherapy consisted of radiotherapy with
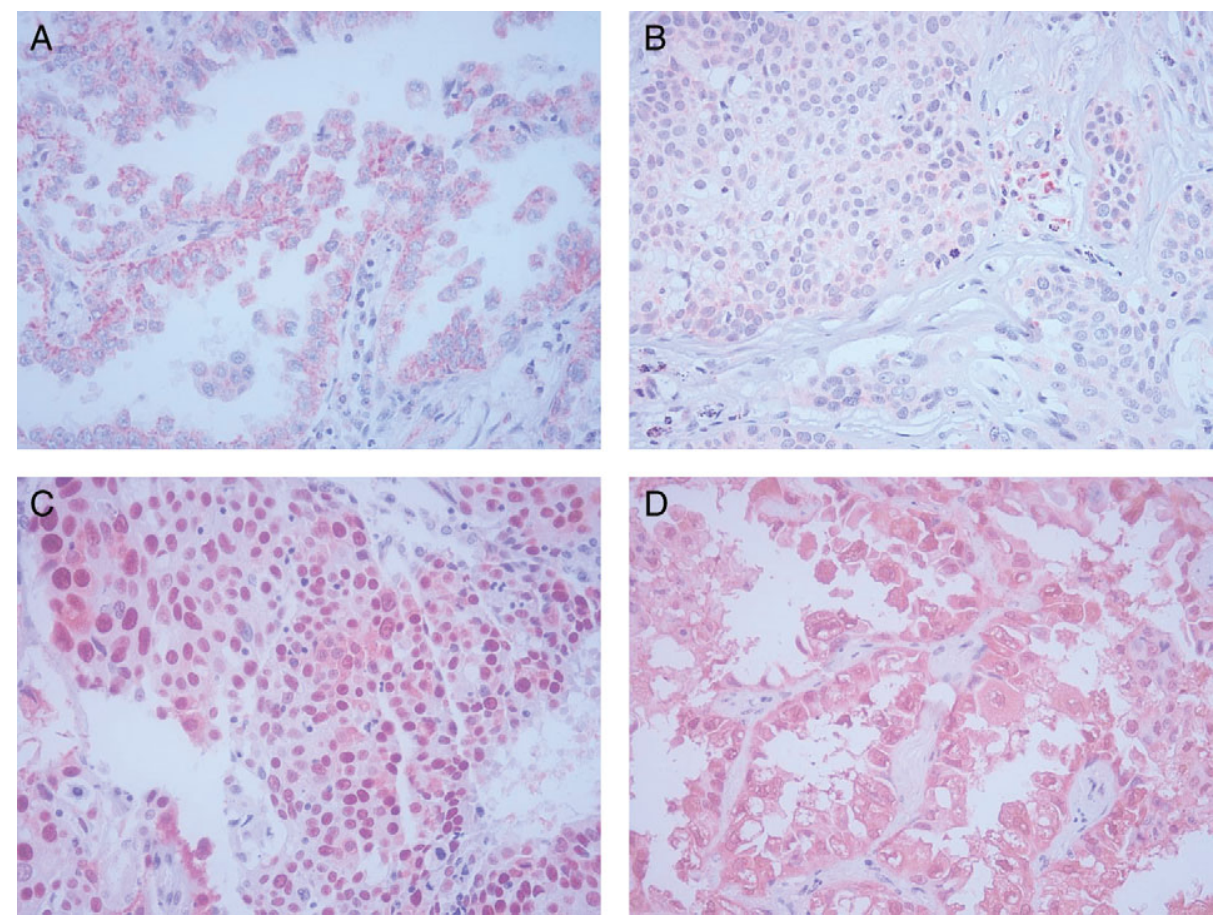

Figure 1. Immunohistochemical staining of apoptosis-related proteins in non-small cell lung cancer $(\times 400)$. (A) High expression of Bax: cytoplasmic staining (Grade 3 in the intensity). (B) Low expression of Bax (Grade 1 in the intensity). (C) High expression of p53: nuclear staining (Grade 3 in the extent). (D) High expression of galectin-3: cytoplasmic staining (Grade 3 in the intensity). 
Table 1. Expression of Bax and clinicopathologic characteristics

\begin{tabular}{|c|c|c|c|}
\hline & $\begin{array}{l}\text { Low } \\
\text { Bax (\%) }\end{array}$ & $\begin{array}{l}\text { High } \\
\text { Bax (\%) }\end{array}$ & $P$ value $^{\mathrm{a}}$ \\
\hline \multicolumn{4}{|l|}{ Gender } \\
\hline Female & $22(14)$ & $23(48)$ & \multirow[t]{2}{*}{$<0.0001$} \\
\hline Male & $135(86)$ & $25(52)$ & \\
\hline \multicolumn{4}{|l|}{ Age } \\
\hline$\leq 63^{\mathrm{b}}$ & $84(54)$ & $28(58)$ & \multirow[t]{2}{*}{0.621} \\
\hline$>63$ & $73(46)$ & $20(42)$ & \\
\hline \multicolumn{4}{|l|}{ History of smoking } \\
\hline Yes & $140(89)$ & $25(52)$ & \multirow[t]{2}{*}{$<0.0001$} \\
\hline No & $17(11)$ & $23(48)$ & \\
\hline \multicolumn{4}{|l|}{ Operation } \\
\hline Lobectomy $^{\mathrm{c}}$ & $100(64)$ & $39(81)$ & \multirow[t]{2}{*}{0.023} \\
\hline Pneumonectomy & $57(36)$ & $9(19)$ & \\
\hline \multicolumn{4}{|l|}{ Histologic types } \\
\hline Squamous & $89(57)$ & $7(15)$ & \multirow[t]{4}{*}{$<0.0001$} \\
\hline Adeno & $54(34)$ & $36(75)$ & \\
\hline Adenosquamous & $7(4)$ & $5(10)$ & \\
\hline Others ${ }^{\mathrm{d}}$ & $7(4)$ & $0(0)$ & \\
\hline \multicolumn{4}{|l|}{ Tumor size (cm) } \\
\hline$\leq 3.9^{\mathrm{e}}$ & $76(48)$ & $29(60)$ & \multirow[t]{2}{*}{0.187} \\
\hline$>3.9$ & $81(52)$ & $19(40)$ & \\
\hline \multicolumn{4}{|l|}{ Stage ${ }^{f}$} \\
\hline I & $72(46)$ & $25(52)$ & \multirow[t]{4}{*}{0.658} \\
\hline II & $38(24)$ & $8(17)$ & \\
\hline IIIA & $35(22)$ & $10(21)$ & \\
\hline IIIB & $12(8)$ & $5(10)$ & \\
\hline \multicolumn{4}{|l|}{ Resection margin } \\
\hline Negative & $140(89)$ & $45(94)$ & \multirow[t]{2}{*}{0.420} \\
\hline Positive & $17(11)$ & $3(6)$ & \\
\hline \multicolumn{4}{|l|}{ Adjuvant treatment } \\
\hline No & $89(57)$ & $28(58)$ & \multirow[t]{4}{*}{0.773} \\
\hline Chemotherapy & $7(4)$ & $1(2)$ & \\
\hline Chemoradiotherapy & $44(28)$ & $12(25)$ & \\
\hline Radiotherapy & $17(11)$ & $7(15)$ & \\
\hline \multicolumn{4}{|l|}{ Expression of $\mathrm{p} 53$} \\
\hline Low & $89(57)$ & $35(73)$ & \multirow[t]{2}{*}{0.063} \\
\hline High & $68(43)$ & $13(27)$ & \\
\hline \multicolumn{4}{|l|}{ Expression of galectin-3 } \\
\hline Low & $88(56)$ & $12(25)$ & \multirow[t]{2}{*}{$<0.0001$} \\
\hline High & $69(44)$ & $36(75)$ & \\
\hline
\end{tabular}

${ }^{a}$ Fisher's exact test. ${ }^{b}$ Median age. ${ }^{c}$ Including two patients with wedge resection. ${ }^{\mathrm{d}}$ Including five patients with large cell carcinoma, one with mucoepidermoid carcinoma and one with carcinosarcoma. ${ }^{e}$ Median longest diameter of primary tumor. ${ }^{\text {f }}$ Post-operative pathologic staging. cisplatin $20 \mathrm{mg} / \mathrm{m}^{2} /$ day for 4 days during Weeks 1 and 4 of radiotherapy.

\section{RADIOTHERAPY}

Radiotherapy was performed using 6- or 15-MV LINAC (CLINAC 2100CD, Varian Medical Systems, Palo Alto, CA, USA). Patients were treated with multiple portals, and a conformal isodose plan was created. The target volume was the bronchial stump, and ipsilateral hilar and mediastinal lymph nodes with a $1-2 \mathrm{~cm}$ margin. The primary tumor bed was included when there was chest wall invasion. The radiation dose to target volume was 50.4 Gy in 27-30 fractions, 5 days/week when corrections for inhomogeneity were not made. After inhomogeneity corrections were made, radiation of 54-60 Gy in 27-30 fractions were delivered to the target volume. Boost radiation of $10-15$ Gy was required when the tumor cells were on the resection margins. The dose to the spinal cord did not exceed 45 Gy.

\section{EvALUATION}

The patients were followed with chest radiography either with or without chest CT scan every 3 months for 2 years, then every 6 months for 3 years and yearly thereafter.

Construction of Tissue Microarray and

Immunohistochemical Staining for Apoptosis-Related PROTEINS

Two representative areas were taken of all cases from paraffin tissue blocks after reviewing the hematoxylineosin-stained slides of the primary tumor. A total of 410 core tissue biopsies (diameter, $1.0 \mathrm{~mm}$ ) were taken and arrayed into three new recipient paraffin blocks. Five-micrometer sections of these tissue array blocks were then cut, placed on charged poly-L-lysine-coated slides and used for immunohistochemical analysis.

Sections from the tissue array were deparaffinized in xylene and were rehydrated in graded alcohol and water. Endogenous peroxidase activity was blocked by treatment with $3 \%$ hydrogen peroxide for $10 \mathrm{~min}$. Sections were treated with a protein-blocking solution and then with primary antibodies, including mouse anti-human monoclonal antibodies against p53 (DO-7, dilution 1:20) and galectin-3 (NCL-GAL3, dilution 1:100) (Novocastra Laboratories Ltd, Newcastle upon Tyne, UK), and rabbit anti-human polyclonal antibody against Bax (dilution 1:1000, DAKO, Carpinteria, CA, USA), for $1 \mathrm{~h}$ at room temperature. After rinsing several times in phosphate-buffered saline, the sections were incubated in biotinylated secondary antibody. Bound antibodies were detected by the streptavidin-biotin method with a Cap-Plus detection kit (Zymed Laboratories 
Table 2. Relationship between the expression of apoptosis-related proteins and subtypes of adenocarcinoma

\begin{tabular}{|c|c|c|c|c|c|c|c|c|c|}
\hline \multirow[t]{2}{*}{ Subtype } & \multicolumn{3}{|l|}{ Bax } & \multicolumn{3}{|l|}{ p53 } & \multicolumn{3}{|c|}{ Galectin-3 } \\
\hline & Low $(\%)$ & High (\%) & $P$ value ${ }^{\mathrm{a}}$ & Low (\%) & High (\%) & $P$ value ${ }^{\mathrm{a}}$ & Low $(\%)$ & High (\%) & $P$ value ${ }^{\mathrm{a}}$ \\
\hline Acinar & $38(70)$ & $22(61)$ & 0.094 & $42(67)$ & $18(67)$ & 0.093 & $21(78)$ & $39(62)$ & 0.622 \\
\hline BAC & $6(11)$ & $10(28)$ & & $12(19)$ & $4(15)$ & & $3(11)$ & $13(21)$ & \\
\hline Papillary & $3(6)$ & $3(8)$ & & $6(10)$ & $0(0)$ & & $1(4)$ & $5(8)$ & \\
\hline Solid $^{b}$ & 7 (13) & $1(3)$ & & $3(5)$ & $5(19)$ & & $2(7)$ & $6(10)$ & \\
\hline
\end{tabular}

BAC, Bronchioloalveolar carcinoma. ${ }^{\mathrm{a}}$ Fisher's exact test. ${ }^{\mathrm{b}}$ Including one patient with signet-ring adenocarcinoma.

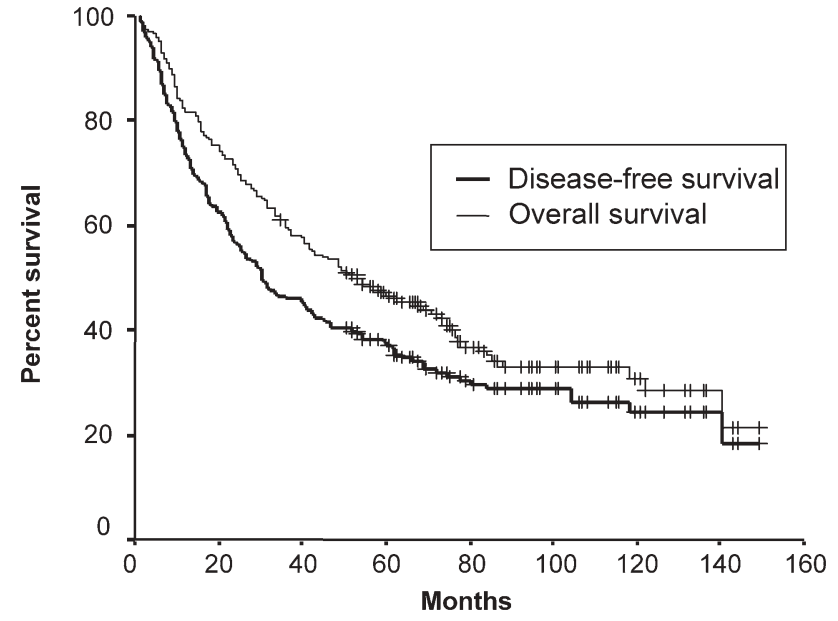

Figure 2. Disease-free and overall survival of resected non-small cell lung cancer patients.

Inc, San Francisco, CA, USA). Slides were rinsed in phosphate-buffered saline, exposed to diaminobenzidine and counterstained with Mayer's hematoxylin. The negative controls for these proteins were made by omitting the primary antibody during the process of immunohistochemical staining. For positive controls of p53 and Bax, a tissue section of colon adenocarcinoma known to have high expression of p53 and lymphocytes in the germinal center were used, respectively, while a tissue section of the tonsil was used as the positive control for galectin-3.

The slides were examined independently by two observers (JHH, JHK) blinded to both clinical and pathologic data. Expression of the apoptosis-related proteins was quantified using a visual grading system based on the extent of staining (percentage of positive tumor cells) (graded on a scale of $0-3 ; 0,0-25 \% ; 1,26-50 \% ; 2,51-75 \% ; 3,>75 \%)$ for p53, and the intensity of staining (graded on a scale of $0-3$; 0 , no staining; 1 , weak staining; 2 , moderate staining; 3 , strong staining) for Bax and galectin-3, respectively. There was close agreement $(>90 \%)$ in the evaluation of apoptosisrelated proteins between both investigators. In case of disagreement, final grading was determined by consensus. Expression of apoptosis-related proteins was classified into high (Grade 2, 3) and low (Grade 0,1) expressions (Fig. 1).

\section{Statistical Analysis}

Disease-free survival (DFS) and overall survival (OS) were calculated using the Kaplan-Meier method (15). DFS was defined as the time from the day of operation to a documented day of recurrence, development of a second primary cancer or death from any other cause. Data on patients who did not experience recurrence were censored at the last follow-up. OS was defined as the time from the day of operation to the time of death; data on survivors were censored at the last follow-up. The differences between the survival curves were tested using the log-rank test and the Wilcoxon test. The Cox proportional-hazards regression model was used to determine the joint effects of several variables on survival (16). The comparison of clinicopathologic characteristics was evaluated with the Fisher's exact test. All statistical analyses were performed two-sided, with SPSS for Windows 12.0 software.

\section{RESULTS}

\section{Patient Characteristics}

The median age of 205 patients with NSCLC was 63 years (range: $30-78$ ), and the median longest diameter of the primary tumor was $3.9 \mathrm{~cm}(1.2-12)$. Twenty-six patients $(13 \%)$ were in Stage IA, $71(35 \%)$ in IB, $7(3 \%)$ in IIA, 39 $(19 \%)$ in IIB, $45(22 \%)$ in IIIA and $17(8 \%)$ in IIIB. One hundred and fifty-eight male patients $(99 \%)$ and seven female patients $(16 \%)$ had a history of smoking (current or previous smoker). In terms of histologic type, 98\% of patients with squamous cell carcinoma had a history of smoking, while $63 \%$ of adenocarcinoma patients and $74 \%$ of patients with other histologic types were current or previous smokers. Other clinicopathologic characteristics of the patients are listed in Table 1.

\section{Association of Expression of Apoptosis-Related Proteins} with Clinicopathologic Characteristics

High expressions of Bax, p53 and galectin-3 were observed in $48(23 \%), 81(40 \%)$ and $105(51 \%)$ patients, respectively. High expression of p53 was associated with male gender $(P=$ 
Table 3. Disease-free and overall survival of the patients according to various characteristics ${ }^{\mathrm{a}}$

\begin{tabular}{|c|c|c|c|c|c|}
\hline Characteristics & $\begin{array}{l}\text { Number } \\
\text { of } \\
\text { patients }\end{array}$ & $\begin{array}{l}\text { 5-year } \\
\text { disease-free } \\
\text { survival } \\
(\%)\end{array}$ & $P$ value $^{\mathrm{b}}$ & $\begin{array}{l}\text { 5-year } \\
\text { overall } \\
\text { survival } \\
(\%)\end{array}$ & $P$ value $^{\mathrm{b}}$ \\
\hline \multicolumn{6}{|l|}{ Gender } \\
\hline Female & 45 & 42 & 0.623 & 55 & 0.327 \\
\hline Male & 153 & 36 & & 44 & \\
\hline \multicolumn{6}{|l|}{ Age } \\
\hline$\leq 63^{\mathrm{c}}$ & 111 & 38 & 0.875 & 47 & 0.648 \\
\hline$>63$ & 87 & 36 & & 46 & \\
\hline \multicolumn{6}{|l|}{ History of smoking } \\
\hline Yes & 158 & 34 & 0.230 & 43 & 0.080 \\
\hline No & 40 & 50 & & 59 & \\
\hline \multicolumn{6}{|l|}{ Operation } \\
\hline Lobectomy ${ }^{\mathrm{d}}$ & 138 & 37 & 0.419 & 49 & 0.063 \\
\hline Pneumonectomy & 60 & 37 & & 42 & \\
\hline \multicolumn{6}{|l|}{ Histologic type } \\
\hline Squamous & 90 & 40 & 0.687 & 46 & 0.746 \\
\hline Non-squamous & 108 & 35 & & 46 & \\
\hline \multicolumn{6}{|l|}{ Tumor size $(\mathrm{cm})$} \\
\hline$\leq 3.9^{\mathrm{e}}$ & 103 & 44 & 0.019 & 52 & 0.026 \\
\hline$>3.9$ & 95 & 29 & & 41 & \\
\hline \multicolumn{6}{|l|}{ Stage ${ }^{\mathrm{f}}$} \\
\hline I & 95 & 51 & $<0.0001$ & 59 & $<0.0001$ \\
\hline II & 45 & 33 & & 44 & \\
\hline IIIA & 44 & 20 & & 29 & \\
\hline IIIB & 14 & 7 & & 21 & \\
\hline \multicolumn{6}{|l|}{ Resection margin } \\
\hline Negative & 181 & 38 & 0.155 & 49 & 0.037 \\
\hline Positive & 17 & 24 & & 24 & \\
\hline \multicolumn{6}{|l|}{ Expression of Bax } \\
\hline Low & 151 & 35 & $0.381^{\mathrm{g}}$ & 45 & $0.247^{\mathrm{h}}$ \\
\hline High & 47 & 45 & & 53 & \\
\hline \multicolumn{6}{|l|}{ Expression of $\mathrm{p} 53$} \\
\hline Low & 121 & 38 & 0.579 & 48 & 0.566 \\
\hline High & 77 & 36 & & 44 & \\
\hline \multicolumn{6}{|c|}{ Expression of galectin-3 } \\
\hline Low & 96 & 34 & 0.237 & 42 & 0.157 \\
\hline High & 102 & 40 & & 50 & \\
\hline
\end{tabular}

${ }^{a}$ Excluding seven patients who died of post-operative complication.

${ }^{b}$ Log-rank test. ${ }^{c}$ Median age. ${ }^{\mathrm{d}}$ Including wedge resection. ${ }^{\mathrm{e}}$ Median longest diameter of primary tumor. ${ }^{\mathrm{f}}$ Post-operative pathologic staging. ${ }^{\mathrm{g}} P=0.103$ according to the Wilcoxon test. ${ }^{\mathrm{h}} P=0.057$ according to the Wilcoxon test

0.024), history of smoking $(P=0.002)$, post-pneumonectomy status $(P=0.046)$ and squamous cell histology $(P=0.033)$. In addition, high expression of galectin-3 correlated with no smoking history $(P=0.023)$, post-lobectomy status
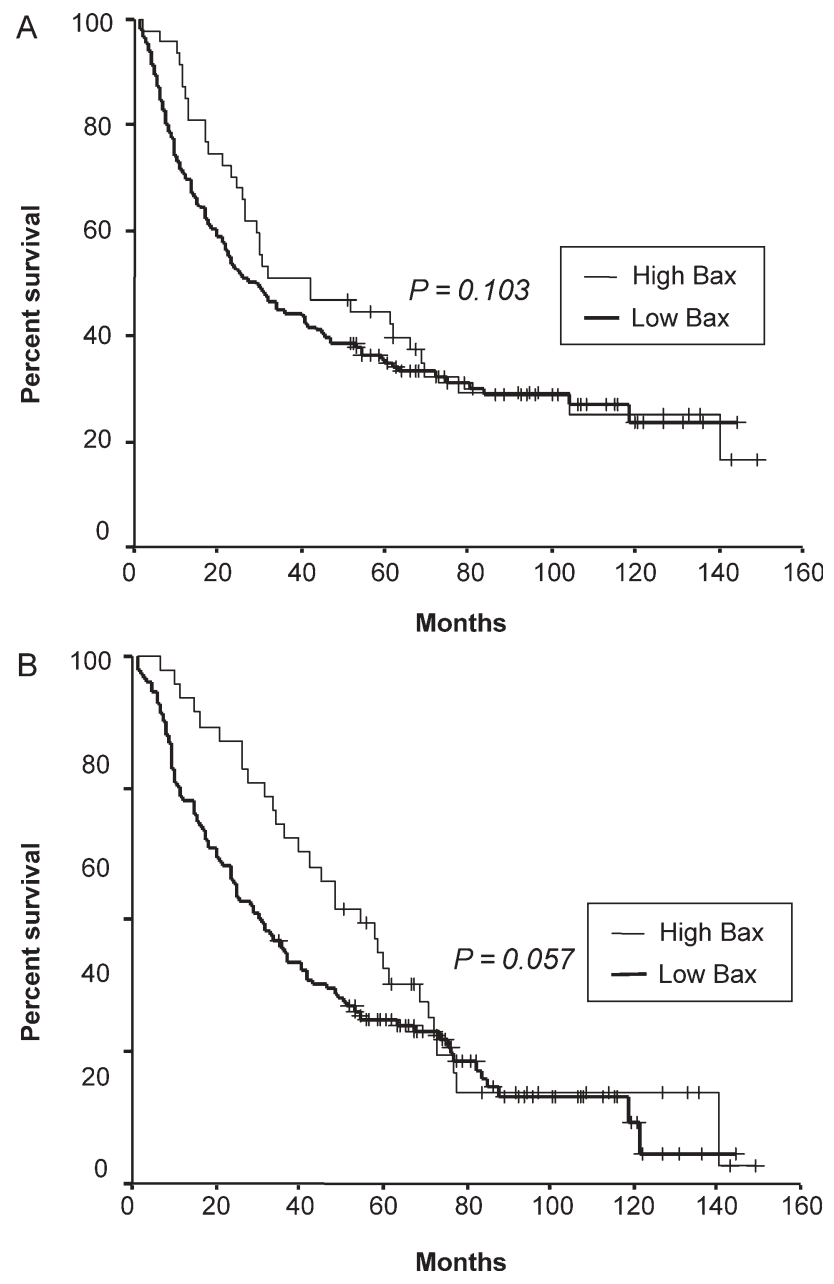

Figure 3. Disease-free survival (A) and overall survival (B) of resected non-small cell lung cancer patients according to the expression of $\operatorname{Bax}(P$ value was obtained using the Wilcoxon test).

$(P=0.011)$, adenocarcinoma $(P<0.0001)$ and negative resection margin $(P=0.018)$. Low expression of Bax was significantly associated with male gender $(P<0.0001)$, history of smoking $(P<0.0001)$, squamous cell histology $(P<$ $0.0001)$ and low expression of galectin-3 $(P<0.0001)$ (Table 1). In terms of subtypes of adenocarcinoma, high expression of Bax showed a trend of correlation with bronchioloalveloar carcinoma $(P=0.094)$ (Table 2).

Association of Expression of Apoptosis-Related Proteins with Patient Outcome

The median follow-up duration of surviving patients was 79 months (range: $35-149$ months), and one patient with recurrence was lost during follow-up because the patient immigrated to another country. At the time of analysis, 132 of 205 patients $(64 \%)$ had died, while 14 patients with either recurrence (11 patients) or second primary cancer (three patients) were alive. Seven patients who died of post-operative complication were excluded from further survival analysis. Five-year 

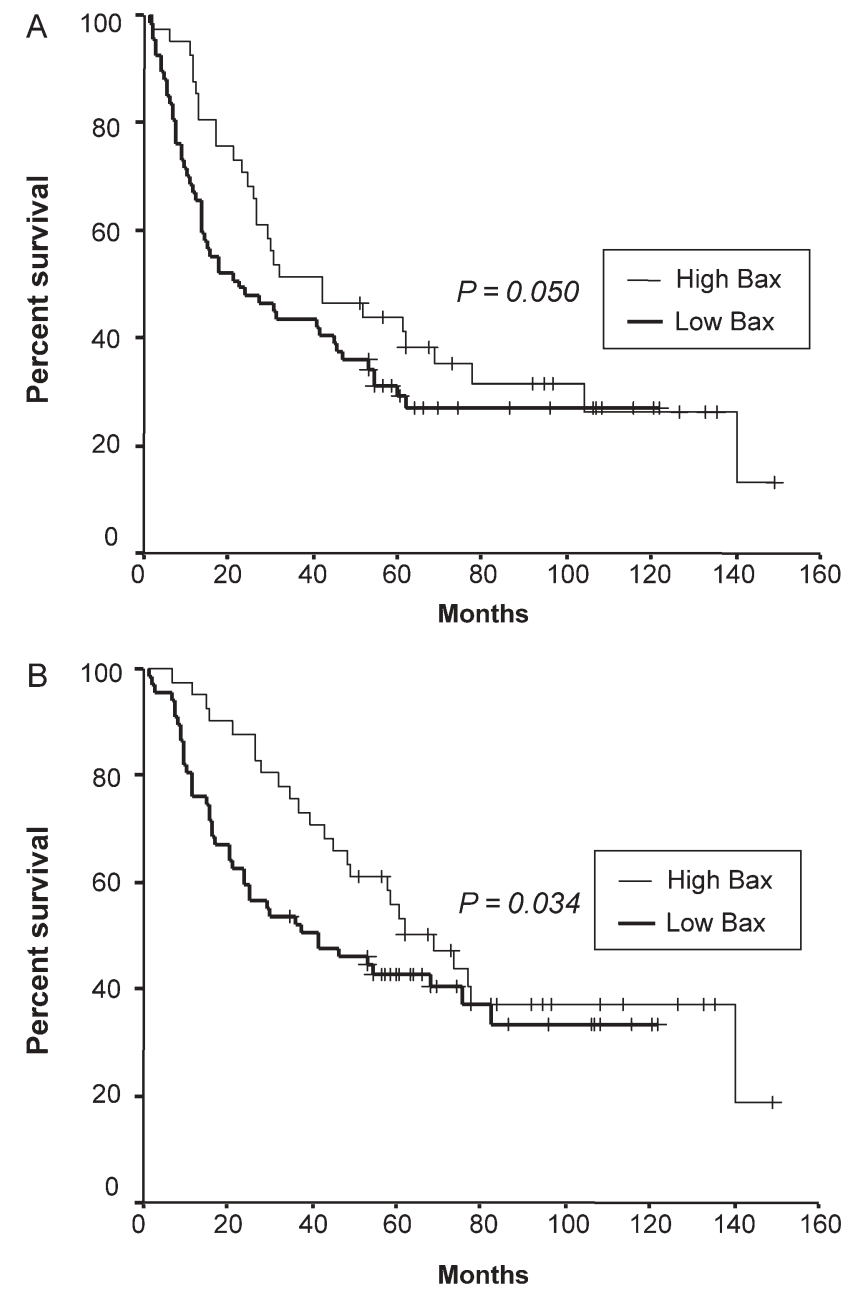

Figure 4. Disease-free survival (A) and overall survival (B) of non-small cell lung cancer patients with non-squamous histology according to the expression of Bax ( $P$ value was obtained using the Wilcoxon test).

DFS and OS of total patients were 37 and $46 \%$, respectively (Fig. 2). High expressions of p53 and galectin-3 were not associated with poor DFS or OS (Table 3). Moreover, there was no significant correlation between low expression of Bax and outcome of patients (Fig. 3 and Table 3). However, in patients with non-squamous histology (108 patients), low expression of Bax was a significant independent predictor of poor DFS $(P=0.017)$ and OS $(P=0.037)$ in multivariate analysis (Fig. 4 and Table 4). In addition, in patients with Stage II or III, low expression of Bax significantly correlated with poor DFS $(P=0.004)$ (Table 5). It was also the most significant independent prognostic factor second only to a large primary tumor size in Stage II or III patients with nonsquamous histology ( $P=0.001$ for DFS, $P=0.013$ for OS) in multivariate analysis as well as in univariate analysis (Fig. 5 and Table 6).

\section{DISCUSSION}

We evaluated the expression of p53, Bax and galectin-3 under the assumption that abnormalities in these apoptosis-related
Table 4. Multivariate analysis of disease-free survival and overall survival in non-squamous histology $(n=108)^{\mathrm{a}}$

\begin{tabular}{|c|c|c|c|c|c|c|}
\hline \multirow[t]{2}{*}{ Prognostic factors } & \multicolumn{3}{|c|}{ Disease-free survival } & \multicolumn{3}{|c|}{ Overall survival } \\
\hline & HR & $95 \% \mathrm{CI}$ & $P$ value ${ }^{\mathrm{b}}$ & HR & $95 \% \mathrm{CI}$ & $\begin{array}{l}P \\
\text { value }^{\mathrm{b}}\end{array}$ \\
\hline \multicolumn{7}{|l|}{ Operation } \\
\hline Lobectomy $^{c}$ & 1.00 & & & 1.00 & & \\
\hline Pneumonectomy & 1.41 & $0.77-2.62$ & 0.269 & 2.63 & $1.45-4.79$ & 0.002 \\
\hline \multicolumn{7}{|l|}{ Tumor size $(\mathrm{cm})$} \\
\hline$\leq 3.9^{\mathrm{d}}$ & 1.00 & & & 1.00 & & \\
\hline$>3.9$ & 2.14 & $1.33-3.45$ & 0.002 & 1.53 & $0.90-2.61$ & 0.118 \\
\hline \multicolumn{7}{|l|}{ Stage $^{e}$} \\
\hline I & 1.00 & & & 1.00 & & \\
\hline II & 2.65 & $1.42-4.96$ & 0.002 & 1.93 & $0.97-3.85$ & 0.062 \\
\hline IIIA & 3.76 & $2.09-6.77$ & $<0.0001$ & 2.58 & $1.40-4.76$ & 0.002 \\
\hline IIIB & 5.23 & $2.08-13.11$ & $<0.0001$ & 3.52 & $1.44-8.62$ & 0.006 \\
\hline \multicolumn{7}{|l|}{ Expression of Bax } \\
\hline High & 1.00 & & & 1.00 & & \\
\hline Low & 1.87 & $1.12-3.14$ & 0.017 & 1.79 & $1.04-3.08$ & 0.037 \\
\hline
\end{tabular}

$\mathrm{HR}$, hazard ratio; CI, confidence interval. ${ }^{a}$ Excluding one patient who died of post-operative complication. ${ }^{\mathrm{b}} \mathrm{Cox}$ proportional-hazards regression model. ${ }^{\mathrm{c}}$ Including wedge resection. ${ }^{\mathrm{d}}$ Median longest diameter of primary tumor

${ }^{\mathrm{e}}$ Post-operative pathologic staging.

proteins may be associated with poor outcome in patients with NSCLC treated with surgical resection either with or without adjuvant treatment.

The most frequently investigated apoptosis-related protein in NSCLC is p53 (11,12,17-22). Although a meta-analysis demonstrated the association of abnormal p53 status with poor prognosis of resected NSCLC, the prognostic significance of p53 still remains controversial $(11,12,17-22)$. Among the reports regarding the role of galectin-3 in NSCLC, one study with only Stage II patients showed the association of high expression of galectin-3 with poor outcome (23-25). The results of the present study showed that high expression of galectin-3 was frequently found in adenocarcinoma, which is consistent with results reported in a previous study (25). In addition, high expressions of p53 and galectin-3 were not associated with poor outcome in patients with resected NSCLC.

The most important finding of the current study was the prognostic significance of the low expression of Bax in patients with resected NSCLC, having non-squamous histology or locally advanced disease (Stages II and III), although it did not predict poor outcome in the entire group of patients. In the present study, the frequency of low expression of Bax was very high $(94 \%)$ in squamous cell carcinoma. Previous studies also revealed the association of low expression of Bax with squamous cell carcinoma in NSCLC $(19,26)$. Therefore, Bax seems to be of little value as a prognostic indicator in NSCLC patients with squamous 
Table 5. Multivariate analysis of disease-free survival and overall survival in Stages II and III $(n=103)^{\mathrm{a}}$

\begin{tabular}{|c|c|c|c|c|c|c|}
\hline \multirow{2}{*}{$\begin{array}{l}\text { Prognostic } \\
\text { factors }\end{array}$} & \multicolumn{3}{|c|}{ Disease-free survival } & \multicolumn{3}{|c|}{ Overall survival } \\
\hline & $\mathrm{HR}$ & $95 \% \mathrm{CI}$ & $P$ value $^{\mathrm{b}}$ & HR & $95 \% \mathrm{CI}$ & $\begin{array}{l}P \\
\text { value }^{\mathrm{t}}\end{array}$ \\
\hline \multicolumn{7}{|l|}{ Age } \\
\hline$\leq 62^{\mathrm{c}}$ & 1.00 & & & 1.00 & & \\
\hline$>62$ & 1.40 & $0.84-2.34$ & 0.202 & 2.06 & $1.21-3.53$ & 0.008 \\
\hline \multicolumn{7}{|l|}{ Histologic type } \\
\hline Squamous & 1.00 & & & 1.00 & & \\
\hline Non-squamous & 2.84 & $1.65-4.89$ & $<0.0001$ & 1.75 & $0.99-3.07$ & 0.052 \\
\hline \multicolumn{7}{|l|}{ Tumor size $(\mathrm{cm})$} \\
\hline$\leq 3.9^{\mathrm{d}}$ & 1.00 & & & 1.00 & & \\
\hline$>3.9$ & 2.00 & $1.26-3.20$ & 0.004 & 1.94 & $1.18-3.19$ & 0.009 \\
\hline \multicolumn{7}{|l|}{ Stage ${ }^{e}$} \\
\hline II & 1.00 & & & 1.00 & & \\
\hline IIIA & 1.51 & $0.91-2.49$ & 0.110 & 1.66 & $0.96-2.86$ & 0.069 \\
\hline IIIB & 1.83 & $0.93-3.57$ & 0.079 & 2.29 & $1.15-4.56$ & 0.019 \\
\hline \multicolumn{7}{|l|}{ Resection margin } \\
\hline Negative & 1.00 & & & 1.00 & & \\
\hline Positive & 2.07 & $1.04-4.13$ & 0.039 & 2.21 & $1.10-4.44$ & 0.026 \\
\hline \multicolumn{7}{|l|}{ Chemotherapy } \\
\hline Yes & 1.00 & & & 1.00 & & \\
\hline No & 1.55 & $0.98-2.45$ & 0.061 & 1.47 & $0.89-2.45$ & 0.136 \\
\hline \multicolumn{7}{|l|}{ Expression of Bax } \\
\hline High & 1.00 & & & 1.00 & & \\
\hline Low & 2.51 & $1.35-4.66$ & 0.004 & 1.77 & $0.92-3.40$ & 0.086 \\
\hline
\end{tabular}

${ }^{\mathrm{a}}$ Excluding five patients who died of post-operative complication. ${ }^{\mathrm{b}} \mathrm{Cox}$ proportional-hazards regression model. ${ }^{\mathrm{c}}$ Median age. ${ }^{\mathrm{d}}$ Median longest diameter of primary tumor. ${ }^{\mathrm{e}}$ Post-operative pathologic staging.

cell histology. On the other hand, in adenocarcinoma, the high expression of Bax demonstrated a trend of correlation with the bronchioloalveolar subtype, which has relatively higher prevalence in non-smokers and females (27). The mechanism of extremely high frequency of low expression of Bax in squamous cell carcinoma remains to be determined. Considering that almost all squamous cell carcinoma patients had a history of smoking and there was a strong correlation between smoking history and low expression of Bax even in adenocarcinoma in the present study $(P=0.014$, data not shown), there is a possibility that smoking might cause the change in the expression of Bax. However, further study is essential to prove this speculation. Recently, Tanaka et al. (28) reported relevant results, which showed that Bax inhibitor-1 gene expression in adenocarcinoma was higher in patients with a bronchioloalveolar component and low smoking index. Since high expression of Bax in adenocarcinoma demonstrated similar significant association with bronchioloalvelolar subtype and no history of smoking in the
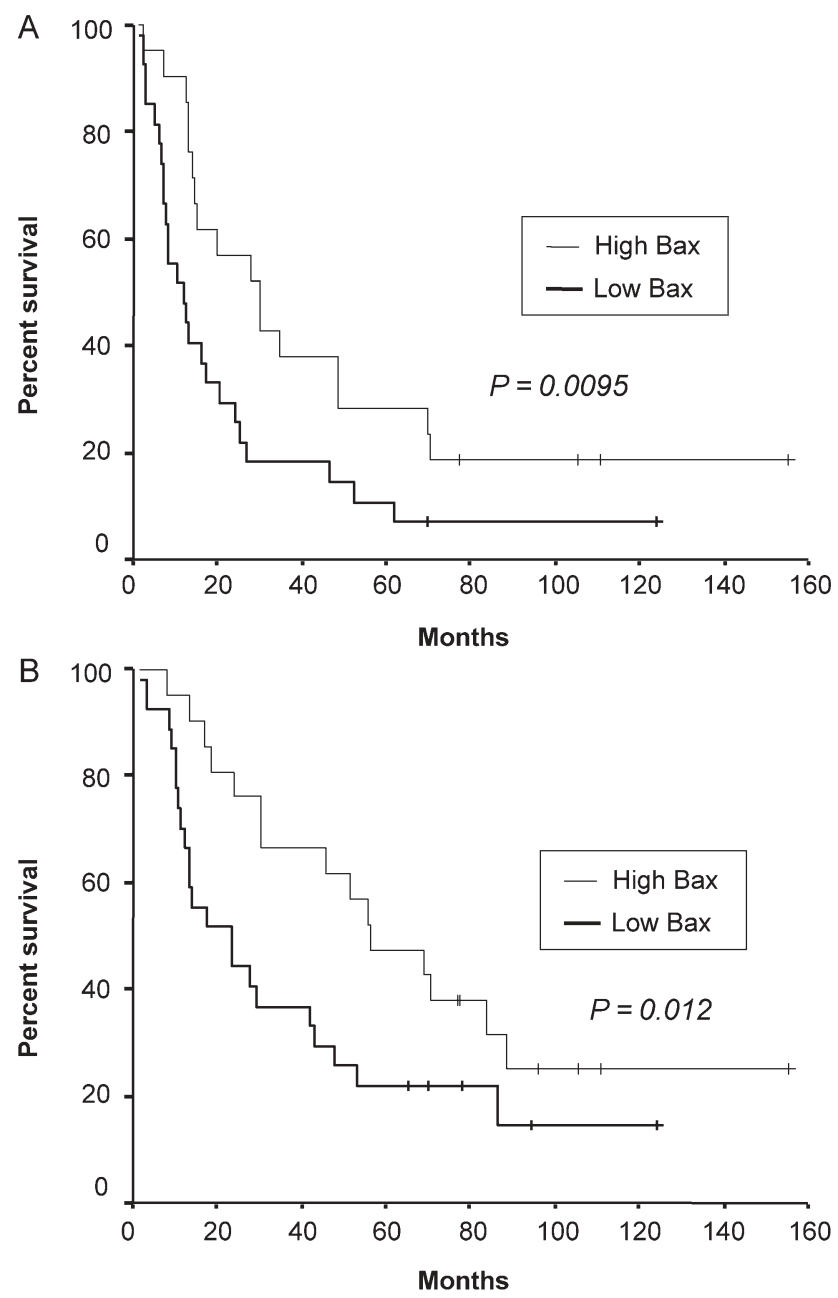

Figure 5. Disease-free survival (A) and overall survival (B) of non-small cell lung cancer patients in Stage II or III with non-squamous histology according to the expression of Bax ( $P$ value was obtained using the Wilcoxon test).

present study, further investigation of the relationship between Bax and the Bax inhibitor-1 may provide valuable information for better understanding of the role of Bax in NSCLC.

To our knowledge, this study is the largest research project that has investigated the role of Bax in NSCLC. Unlike for $\mathrm{p} 53$ or Bcl-2, there are fewer studies that discuss the prognostic significance of Bax in NSCLC $(11,12,19-$ $22,29-31)$. In addition, only one study that investigated 61 patients in a predominantly advanced stage (Stage IV, 54\%) demonstrated the correlation between a low expression of Bax and poor outcome (29).

The poor outcome of patients with low expression of Bax may be attributed to the intrinsic aggressiveness of the tumor $(11,32)$. The prognostic value of low expression of Bax was more significant in patients with non-squamous histology, which had relatively lower proportion of current or previous smokers compared with squamous cell carcinoma in the present study. In addition, there was a very strong association between smoking history and low expression of Bax in 
Table 6. Multivariate analysis of disease-free survival and overall survival in Stages II and III with non-squamous histology $(n=48)^{\mathrm{a}}$

\begin{tabular}{|c|c|c|c|c|c|c|}
\hline \multirow[t]{2}{*}{ Prognostic factors } & \multicolumn{3}{|c|}{ Disease-free survival } & \multicolumn{3}{|c|}{ Overall survival } \\
\hline & $\mathrm{HR}$ & $95 \% \mathrm{CI}$ & $P$ value $^{\mathrm{b}}$ & $\mathrm{HR}$ & $95 \% \mathrm{CI}$ & $\begin{array}{l}P \\
\text { value }^{\mathrm{b}}\end{array}$ \\
\hline \multicolumn{7}{|l|}{ Operation } \\
\hline Lobectomy & 1.00 & & & 1.00 & & \\
\hline Pneumonectomy & 1.45 & $0.67-3.13$ & 0.347 & 2.36 & $1.11-4.99$ & 0.025 \\
\hline \multicolumn{7}{|l|}{ Tumor size $^{\mathrm{c}}(\mathrm{cm})$} \\
\hline$\leq 3.9$ & 1.00 & & & 1.00 & & \\
\hline$>3.9$ & 4.12 & $2.01-8.43$ & $<0.0001$ & 2.69 & $1.25-5.83$ & 0.012 \\
\hline \multicolumn{7}{|l|}{ Stage $^{d}$} \\
\hline II & 1.00 & & & 1.00 & & \\
\hline III & 1.41 & $0.74-2.68$ & 0.291 & 1.42 & $0.62-3.27$ & 0.407 \\
\hline \multicolumn{7}{|l|}{ Expression of Bax } \\
\hline High & 1.00 & & & 1.00 & & \\
\hline Low & 3.05 & $1.56-5.97$ & 0.001 & 2.34 & $1.20-4.56$ & 0.013 \\
\hline
\end{tabular}

${ }^{\mathrm{a}}$ Excluding one patient who died of post-operative complication. ${ }^{\mathrm{b}} \mathrm{Cox}$ proportional-hazards regression model. ${ }^{\mathrm{c}}$ Median longest diameter of primary tumor. ${ }^{\mathrm{d}}$ Post-operative pathologic staging.

patients with non-squamous histology $(P<0.0001$, data not shown). These findings suggest the possibility that more extensive genetic damage such as low expression of Bax caused by smoking may result in intrinsic aggressiveness of the tumor, leading to poor outcome. On the other hand, we may suppose that resistance to adjuvant chemotherapy or radiotherapy in tumors with low expression of Bax may be the cause of poor prognosis, based on the results of the present study, which demonstrated that the low expression of Bax predicted poor DFS in Stages II or III when adjuvant treatments were commonly given $(80 \%$ of patients) $(8,11-13)$.

The present study has several potential limitations. First, this is a retrospective analysis from a single institution with patients' cohort within a relatively long period of time. Second, adjuvant chemotherapy was individualized according to the discretion of the treating oncologists, which resulted in rather heterogeneous chemotherapy regimens, although cisplatin was included in almost all. Third, the low expression of Bax did not demonstrate prognostic significance in the entire study population.

The association of low expression of Bax with poor DFS in Stages II or III has a clinical relevance, because adjuvant chemotherapy has recently been established as a standard of care for resected Stage II or III NSCLC, and the majority of patients in these stages in the current study received adjuvant chemotherapy either with or without radiotherapy $(62 \%)$ $(2,4-7)$. In Stage II or III patients with non-squamous histology, the 5-year OS of patients with low expression of Bax was significantly lower compared with that of high expression (22 versus $43 \%, P=0.012$, Wilcoxon test), while low expression of Bax was one of the significant independent predictors of poor prognosis in multivariate analysis. Therefore, the present study suggests that locally advanced (Stage II or III) non-squamous NSCLC patients with low expression of Bax may require more effective adjuvant treatment or an intensified follow-up.

In conclusion, low expression of Bax was significantly associated with the poor outcome in patients with nonsquamous NSCLC. If the prognostic significance of low expression of Bax is validated by further prospective studies with larger numbers of patients, a relatively simple immunohistochemical staining of surgical specimens for the Bax protein may provide valuable information to the oncologist for selecting effective adjuvant treatments or follow-up strategies.

\section{Funding}

Ajou University Medical Center, Suwon, Korea. Funding to pay the Open Access publication charges for this article was provided by Ajou University Medical Center.

\section{Acknowledgements}

The authors are grateful to Geum Sook Jeong for administrative assistance in preparing and submitting the manuscript. We would also like to thank Joo Yeon Kim for proofreading the manuscript.

\section{References}

1. Bae J, Won Y, Jung K, Suh K, Yun Y, Shin M. Survival of Korean cancer patients diagnosed in 1995. Cancer Res Treat 2002;34:319-25.

2. Spira A, Ettinger DS. Multidisciplinary management of lung cancer. N Engl J Med 2004;350:379-92.

3. Mountain CF. Revisions in the International System for Staging Lung Cancer. Chest 1997;111:1710-7.

4. Arriagada R, Bergman B, Dunant A, Le Chevalier T, Pignon JP, Vansteenkiste J. Cisplatin-based adjuvant chemotherapy in patients with completely resected non-small-cell lung cancer. $N$ Engl $J$ Med 2004;350:351-60.

5. Winton T, Livingston R, Johnson D, Rigas J, Johnston M, Butts C, et al. Vinorelbine plus cisplatin vs. observation in resected non-small-cell lung cancer. N Engl J Med 2005;352:2589-97.

6. Douillard JY, Rosell R, De Lena M, Carpagnano F, Ramlau R, Gonzales-Larriba JL, et al. Adjuvant vinorelbine plus cisplatin versus observation in patients with completely resected stage IB-IIIA non-small-cell lung cancer (Adjuvant Navelbine International Trialist Association [ANITA]): a randomised controlled trial. Lancet Oncol 2006;7:719-27

7. Pignon J, Tribodet H, Scagliotti G. A pooled analysis of five randomized clinical trials including 4,584 patients. $J$ Clin Oncol 2006;24(Suppl.):366.

8. Fulda S, Debatin KM. Extrinsic versus intrinsic apoptosis pathways in anticancer chemotherapy. Oncogene 2006;25:4798-811.

9. Jurgensmeier JM, Xie Z, Deveraux Q, Ellerby L, Bredesen D, Reed JC. Bax directly induces release of cytochrome $c$ from isolated mitochondria. Proc Natl Acad Sci USA 1998;95:4997-5002.

10. Yang RY, Liu FT. Galectins in cell growth and apoptosis. Cell Mol Life Sci 2003;60:267-76.

11. Singhal S, Vachani A, Antin-Ozerkis D, Kaiser LR, Albelda SM. Prognostic implications of cell cycle, apoptosis, and angiogenesis biomarkers in non-small cell lung cancer: a review. Clin Cancer Res $2005 ; 11: 3974-86$ 
12. Zhu CQ, Shih W, Ling CH, Tsao MS. Immunohistochemical markers of prognosis in non-small cell lung cancer: a review and proposal for a multiphase approach to marker evaluation. J Clin Pathol 2006;59: 790-800.

13. Ling CC, Guo M, Chen $\mathrm{CH}$, Deloherey T. Radiation-induced apoptosis: effects of cell age and dose fractionation. Cancer Res 1995;55: 5207-12.

14. Frederick L. AJCC Cancer Staging Manual. Lippincott Raven, 2002.

15. Kaplan E, Meier P. Non-parametric estimations from incomplete observations. J AM Stat Assoc 1958;53:457-81.

16. Cox D. Regression model and life-tables. $J R$ Stat Soc Ser 1972;34:187-220.

17. Steels E, Paesmans M, Berghmans T. Role of P53 as a prognostic factor for survival in lung cancer: a systematic review of the literature with a meta-analysis. Eur Respir J 2001;18:705-19.

18. Lee JS, Yoon A, Kalapurakal SK, Ro JY, Lee JJ, Tu N, et al. Expression of p53 oncoprotein in non-small-cell lung cancer: a favorable prognostic factor. J Clin Oncol 1995;13:1893-903.

19. Apolinario RM, van der Valk P, de Jong JS, Deville W, van Ark-Otte J, Dingemans AM, et al. Prognostic value of the expression of $\mathrm{p} 53$, bcl-2, and bax oncoproteins, and neovascularization in patients with radically resected non-small-cell lung cancer. $J$ Clin Oncol 1997; 15:2456-66.

20. Borner MM, Brousset P, Pfanner-Meyer B, Bacchi M, Vonlanthen S, Hotz MA, et al. Expression of apoptosis regulatory proteins of the Bcl-2 family and p53 in primary resected non-small-cell lung cancer. Br J Cancer 1999;79:952-8.

21. Chen Y, Sato M, Fujimura S, Endo C, Sakurada A, Aikawa H, et al. Expression of Bcl-2, Bax, and p53 proteins in carcinogenesis of squamous cell lung cancer. Anticancer Res 1999;19:1351-6.

22. Groeger AM, Esposito V, De Luca A, Cassandro R, Tonini G, Ambrogi V, et al. Prognostic value of immunohistochemical expression of p53, bax, $\mathrm{Bcl}-2$ and $\mathrm{Bcl}-\mathrm{xL}$ in resected non-small-cell lung cancers. Histopathology 2004;44:54-63.
23. Szoke T, Kayser K, Baumhakel JD, Trojan I, Furak J, Tiszlavicz L, et al. Prognostic significance of endogenous adhesion/growth-regulatory lectins in lung cancer. Oncology 2005;69:167-74.

24. Szoke T, Kayser K, Trojan I, Kayser G, Furak J, Tiszlavicz L, et al. The role of microvascularization and growth/adhesion-regulatory lectins in the prognosis of non-small cell lung cancer in stage II. Eur. J Cardiothorac Surg 2007;31:783-7.

25. Puglisi F, Minisini AM, Barbone F, Intersimone D, Aprile G, Puppin C, et al. Galectin-3 expression in non-small cell lung carcinoma. Cancer Lett 2004;212:233-9.

26. Porebska I, Wyrodek E, Kosacka M, Adamiak J, Jankowska R, Harlozinska-Szmyrka A. Apoptotic markers p53, Bcl-2 and Bax in primary lung cancer. In Vivo 2006;20:599-604.

27. Christiani DC PW, DeMartini JC, Linnoila RI, Malkinson AM, Onn A, Politi KA, et al. BAC consensus conference, November 4-6, 2004: epidemiology, pathogenesis, and preclinical models. J Thorac Oncol 2006;1(Suppl. 9):S2-7.

28. Tanaka R, Ishiyama T, Uchihara T, Inadome Y, Iijima T, Morishita Y, et al. Expression of the Bax inhibitor-1 gene in pulmonary adenocarcinoma. Cancer 2006;106:648-53.

29. Gessner C, Liebers U, Kuhn H, Stiehl P, Witt C, Schauer J, et al. BAX and p16INK4A are independent positive prognostic markers for advanced tumour stage of nonsmall cell lung cancer. Eur Respir $J$ 2002; 19:134-40.

30. Hanaoka T, Nakayama J, Haniuda M, Sato T. Immunohistochemical demonstration of apoptosis-regulated proteins, Bcl-2, and Bax, in resected non-small-cell lung cancers. Int J Clin Pract 2002;7:152-8.

31. Yaren A, Oztop I, Kargi A. Bax, bcl-2, and c-kit expression in non-small-cell lung cancer and their effects on prognosis. Int J Clin Pract 2006;60:675-82.

32. Kang SY, Han JH, Lee KJ, Choi JH, Park JI, Kim HI, et al. Low expression of Bax predicts poor prognosis in patients with locally advanced esophageal cancer treated with definitive chemoradiotherapy. Clin Cancer Res 2007;13:4146-53. 